\title{
Pola Perkembangan Harga Lahan di Kawasan Koridor Jalan Arteri Porong Sidoarjo
}

\author{
Nur Fitriah Andriani dan Ardy Maulidy Navastara \\ Jurusan Perencanaan Wilayah dan Kota, Fakultas Teknik Sipil dan Perencanaan, \\ Institut Teknologi Sepuluh Nopember (ITS) \\ Jl. Arief Rahman Hakim, Surabaya 60111 Indonesia \\ e-mail: ardy.navastara@urplan.its.ac.id
}

\begin{abstract}
Abstrak- Menurut RTRW Kabupaten Sidoarjo Tahun 20092029 dalam arahan pemanfaatan ruang disebutkan bahwa salah satu indikasi program di sektor pekerjaan umum adalah adanya proyek pembangunan Jalan Arteri Porong. Terbangunnya Jalan Arteri Porong mendorong meningkatnya tingkat aksesibilitas yang berpengaruh terhadap nilai lahan kawasan. Hal tersebut juga berpengaruh juga terhadap peningkatan harga lahan sebesar $50 \%$ untuk tanah kering dan $317 \%$ untuk tanah sawah.. Kenaikan harga lahan tersebut merupakan kenaikan yang tidak wajar. Jika dibiarkan secara terus menerus, akan dapat menghambat rencana pengembangan kawasan. Penelitian ini bertujuan untuk mengetahui pola perkembangan harga lahan di koridor Jalan Arteri Porong Sidoarjo. Teknik analisis yang digunakan dalam penelitian ini adalah teknik interpolasi dengan menggunakan aplikasi Surfer 10. Hasil penelitian ini menghasilkan peta pola persebaran harga lahan 3 tahun terakhir (2013-2015). Berdasarkan pemetaan persebaran harga lahan yang telah dilakukan dapat diketahui bahwa pada tahun 2013-2015 telah terjadi perkembangan harga lahan di wilayah penelitian. Pada tahun 2013 ke tahun 2014, harga lahan di wilayah penelitian berkembang di sekitar Kelurahan Juwet Kenongo dan Porong yang merupakan pusat kegiatan. Dalam perkembangannya, dapat terlihat dalam peta bahwa harga lahan yang memiliki kisaran cukup tinggi semakin meluas di antara kedua kelurahan tersebut. Harga tertinggi pada tahun 2013 ke tahun 2014 berselisih sebesar 120.000 hingga 200.000 rupiah. Tahun 2015 harga lahan mengalami perembetan perkembangan yang semakin meluas di sekitar pusat kegiatan dan muncul perkembangan harga lahan yang cukup tinggi di sepanjang koridor Jalan Arteri.
\end{abstract}

Kata Kunci-harga lahan, kawasan koridor Jalan Arteri Porong, pola perkembangan

\section{PENDAHULUAN}

$\mathrm{S}_{\mathrm{p}}^{\mathrm{E}}$ EIRING dengan berjalannya waktu, kota mengalami perkembangan lahan sebagai akibat dari pertambahan penduduk, perubahan sosio-ekonomi dan budayanya serta interaksinya dengan kota-kota lain dan daerah di sekitarnya. Dari waktu ke waktu, kota sebagai perwujudan spasial cenderung mengalami perubahan baik fisik maupun nonfisik, begitu juga dengan fungsi-fungsi perkotaan [1]. Setiap bentuk perubahan pemanfaatan lahan pada suatu bidang tertentu akan berpotensi mempengaruhi bidang penggunaan lahan di dekatnya [2]. Salah satu penyebab terjadinya perubahan suatu guna lahan adalah jaringan infrastruktur terutama jaringan transportasi [3]. Adanya jaringan transportasi akan mempengaruhi tinggi rendahnya tingkat aksesibilitas. Semakin banyak sistem jaringan yang tersedia pada daerah tersebut maka semakin mudah aksesibilitas yang didapat begitu pula sebaliknya semakin rendah tingkat aksesibilitas yang didapat maka semakin sulit daerah itu dijangkau dari daerah lainnya. Faktor aksesibilitas merupakan salah satu faktor yang berpengaruh terhadap nilai lahan di suatu kawasan. Hal tersebut juga akan berpengaruh terhadap harga lahan di kawasan tersebut, karena harga lahan dan nilai lahan memiliki keterkaitan fungsional dalam pengertiannya, di mana harga lahan umumnya ditentukan oleh nilai lahan atau harga lahan akan mencerminkan tinggi rendahnya nilai lahan [4].

Dalam arahan pemanfaatan ruang disebutkan bahwa salah satu indikasi program di sektor pekerjaan umum adalah adanya proyek pembangunan Jalan Arteri Porong [5]. Dalam melancarkan kegiatan antar wilayah terutama yang melintasi Jalan Raya Porong, Badan Penanggulangan Lumpur Sidoarjo (BPLS) menjadi penanggung jawab utama untuk membangun jalan tersebut sebagai strategi dalam mengatasi kemacetan di Jalan Raya Porong yang disebabkan karena kondisi jalan yang kurang baik akibat bencana lumpur LAPINDO. Hal tersebut menyebabkan jalan tersebut tidak dapat berfungsi secara optimal. Terbangunnya Jalan Arteri Porong Sidoarjo akan meningkatkan tingkat aksesibilitas di sekitar kawasan. Adanya kemudahan aksesibilitas yang ada akan mendorong meningkatnya harga lahan di sekitar jalan tersebut, karena letaknya yang strategis. Peningkatan harga lahan di kawasan tersebut berkisar sebesar 317\% untuk tanah sawah dan 50\% untuk tanah kering [6]. Kondisi faktual tersebut menunjukkan adanya perbedaan harga lahan yang diyakini akan terus berlangsung sepanjang koridor Jalan Arteri Porong. Hal ini disebabkan karena kawasan koridor jalan memiliki tingkat aksesibilitas yang tinggi, sehingga sangat berpotensi untuk pengembangan lahan. Adanya pengembangan lahan yang intensif dapat mempengaruhi harga lahan [7].

Kenaikan harga lahan yang terjadi di kawasan koridor Jalan Arteri Porong merupakan kenaikan yang tidak wajar. Jika dibiarkan secara terus menerus, akan dapat menghambat rencana pengembangan kawasan. Oleh karena itu, dalam mendukung kegiatan pengembangan lahan di sekitar kawasan, perlu diketahui pola perkembangan harga lahannya guna membantu dalam proses perencanaan ataupun pengambilan keputusan. Penelitian ini bertujuan untuk mengetahui pola perkembangan harga lahan di koridor Jalan Arteri Porong Sidoarjo. Ruang lingkup wilayah penelitian ini adalah di 
sepanjang koridor Jalan Arteri Porong, di mana terdapat 6 kelurahan/desa yang berbatasan langsung dengan jalan arteri dan masih terkena pengaruh adanya pusat kegiatan. Kelurahan/desa tersebut diantaranya, Desa Pamotan, Desa Kesambi, Kelurahan Gedang, Kelurahan Juwet Kenongo, Kelurahan Porong, dan Desa Kebonagung. Selain itu, pada kelurahan/desa tersebut juga dilalui oleh jalan kolektor primer yang menghubungkan langsung ke Jalan Arteri Porong. Sehingga, hal tersebut menyebabkan kawasan sekitar jalan tersebut juga berpotensi mendapatkan pengaruh dari keberadaan Jalan Arteri Porong.

\section{METODE PENELITIAN}

Pendekatan yang digunakan pada penelitian ini adalah pendekatan peneltian kuantitatif yang berdasarkan paradigma positivisme. Penelitian ini bersifat deskriptif kuantitatif. Dalam pengumpulan datanya menggunakan survei primer, yaitu wawancara kepada penduduk setempat untuk mendapatkan informasi harga lahan di wilayah penelitian pada 3 tahun terakhir (2013-2015). Untuk memetakan persebaran harga lahan, populasinya adalah seluruh jumlah persil kawasan terbangun di wilayah penelitian. Untuk menghitung jumlah persil dilakukan digitasi pada peta wilayah penelitian dengan menggunakan software ArcGIS 10.1. Sampel yang digunakan merupakan sampel probabilistik. Teknik sampling yang digunakan adalah simple random sampling, karena mayoritas karakteristik wilayah penelitian adalah sejenis yaitu berupa permukiman dan persawahan. Berdasarkan perhitungan populasi melalui digitasi persil terbangun yang dibantu dengan aplikasi ArcGIS 10.1, jumlah populasi dari persil bangunan di wilayah penelitian adalah 9393 persil dan setelah dihitung menggunakan rumus Slovin, sampel dari penelitian ini berjumlah 384 persil.

Setelah didapatkan jumlah sampel sebesar 384 sampel, maka sebelum dilakukan survey kuisioner dilakukan pengacakan populasi menggunakan salah satu fungsi di Microsoft Excel untuk mendapatkan jumlah sampel acak. Adapun langkahlangkahnya sebagai berikut:

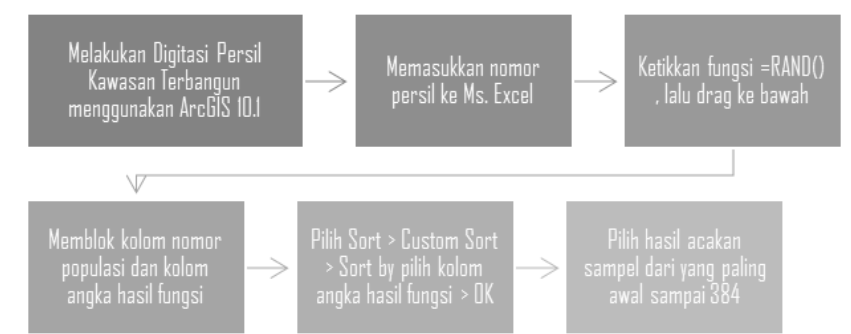

Gambar 1. Langkah-Langkah Pengacakan Sampel Menggunakan Microsoft Excel

Sumber: Penulis, 2016

Dari langkah-langkah di atas, sehingga didapatkan sampel sebanyak 384 dan sudah acak di wilayah penelitian. Langkahlangkah analisis selanjutnya adalah sebagai berikut:

1. Dari hasil sampel acak tersebut, lalu dipetakan ke dalam peta titik-titik sampel survey harga lahan.
2. Untuk keperluan analisis, ditambahkan beberapa titik tambahan di luar wilayah penelitian yang bertujuan agar pada saat akan memperoleh memetakan pola harga lahan, wilayah yang berada di luar wilayah penelitian tidak dianggap memiliki harga lahan sama dengan 0 .

3. Dari peta persebaran titik-titik sampel tersebut, lalu dilakukan survey kuisioner-semi wawancara kepada responden yang berada di persil bangunan yang telah diacak.

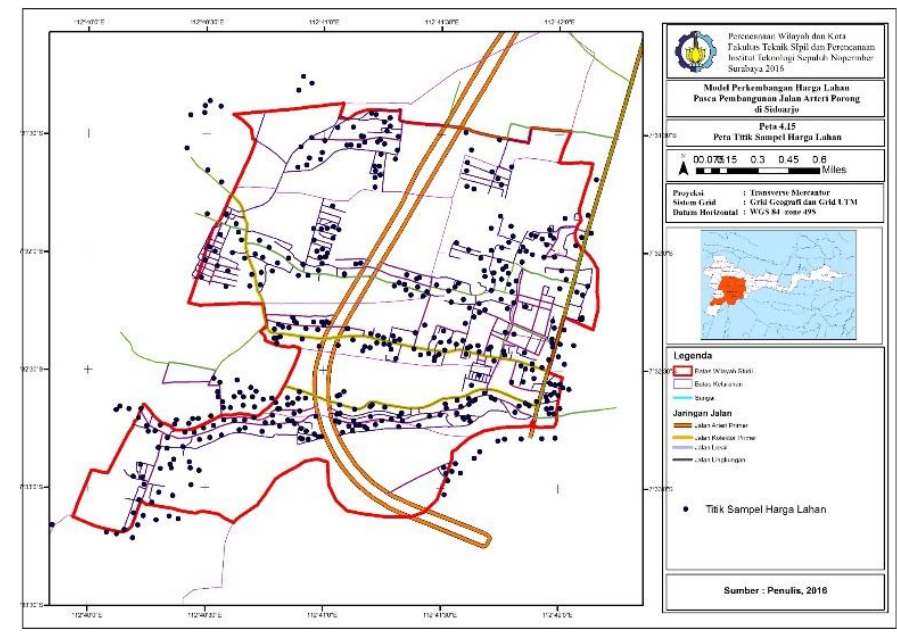

Gambar 2. Titik Sampel Sebaran Harga Lahan

Sumber:Penulis, 2016

4. Untuk memperoleh data harga lahan yang benar-benar menggambarkan data harga lahan di wilayah penelitian pada tahun-tahun yang telah ditentukan, pada saat survey kuisioner juga dilakukan wawancara sebagai tahap konfirmasi kebenaran informasi yang diberikan oleh responden. Selain itu, informasi harga lahan pada tahun 2014 yang diperoleh dari responden juga dikomparasikan dengan informasi Zona Nilai Tanah (ZNT) yang dimiliki oleh BPN dan setelah dihitung, hasil rataratanya menunjukkan sesuai dengan ZNT.

5. Informasi harga lahan yang telah diperoleh dari survey kuisioner selanjutnya direkapitulasi ke dalam Ms. excel yang kemudian dimasukkan ke software ArcGIS sesuai dengan koordinat titik-titik wilayah penelitiannya.

6. Menyalin data harga lahan beserta koordinatnya dari data attribute table di ArcGIS ke Ms. Excel dan memberi nama kolom harga lahan sebagai ' $Z$ '.

7. Langkah selanjutnya yaitu melakukan analisis menggunakan teknik interpolasi dengan bantuan aplikasi Surfer 10 untuk menghasilkan peta kontur harga lahan per tahunnya. Peta kontur tersebut akan menunjukkan sebaran tinggi rendahnya harga lahan di wilayah penelitian.

\section{ANALISIS DAN PEMBAHASAN}

Berdasarkan hasil analisis menggunakan teknik interpolasi dengan menggunakan aplikasi Surfer 10, dihasilkan peta sebaran harga lahan tahun 2013-2015 (lihat gambar 3, 4, dan 5). 


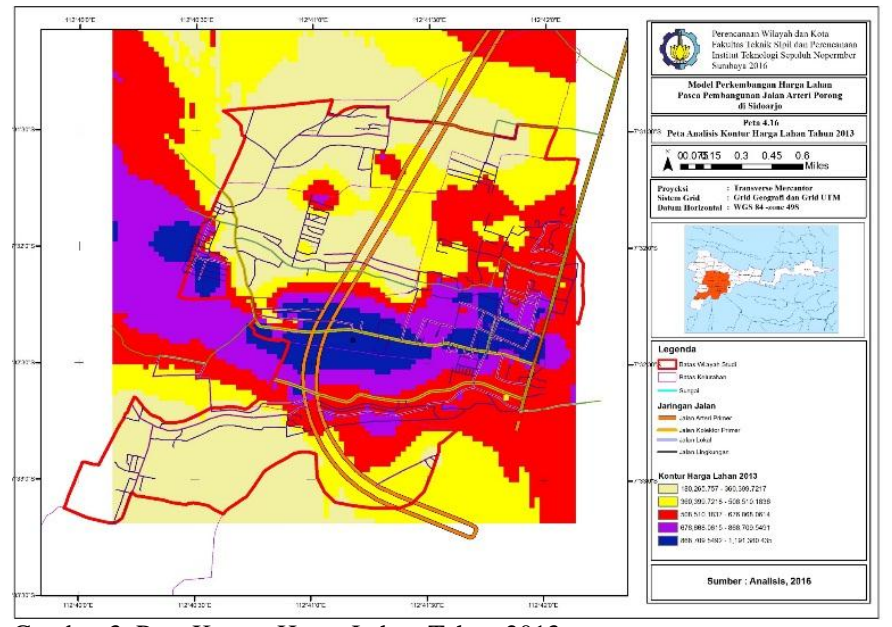

Gambar 3. Peta Kontur Harga Lahan Tahun 2013 Sumber: Hasil Analisis, 2016

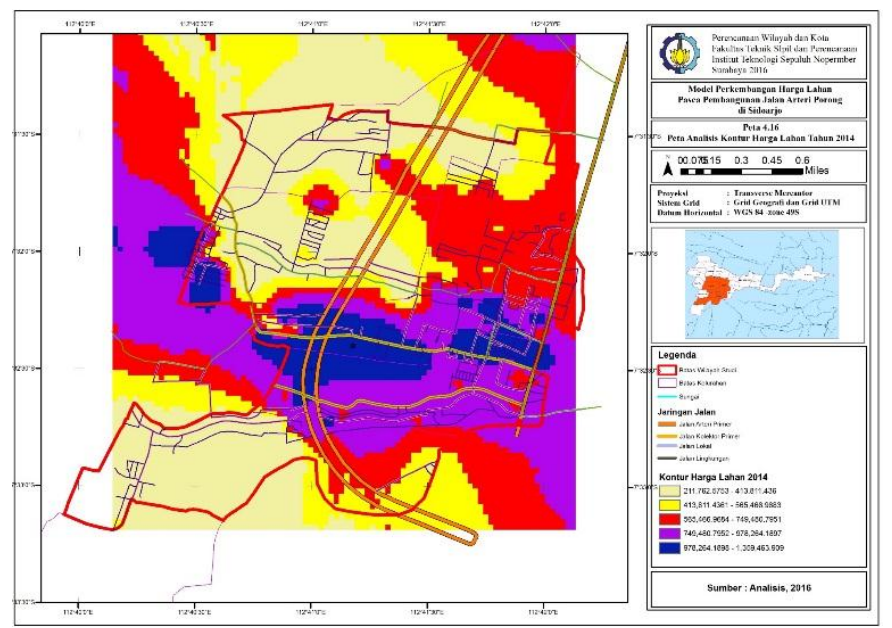

Gambar 4. Peta Kontur Harga Lahan Tahun 2014 Sumber: Hasil Analisis, 2016

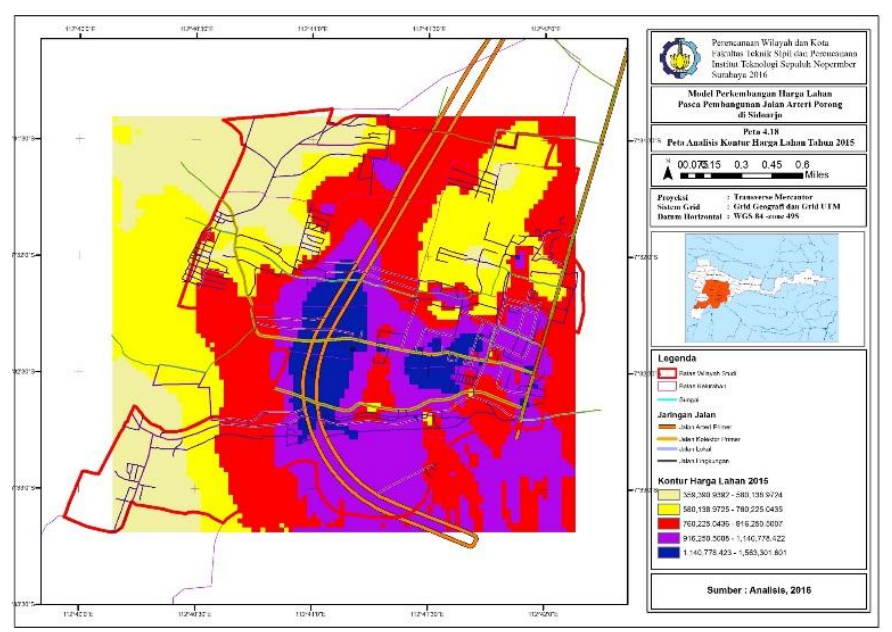

Gambar 5. Peta Kontur Harga Lahan 2015

Sumber: Hasil Analisis, 2016

Dari peta persebaran harga lahan pada 3 tahun terakhir, yaitu pada tahun 2013-2015 terlihat ada perkembangan di setiap tahunnya. Pada tahun 2013, harga lahan terendah di wilayah penelitian berkisar sebesar 180.000 rupiah yang berada di Desa Pamotan. Sedangkan, harga tertingginya berkisar antara
850.000-1.100.000 rupiah yang berada di Kelurahan Juwet Kenongo yang merupakan pusat kegiatan dan Kelurahan Porong yang dekat dengan pusat kegiatan. Lalu, pada tahun 2014 harga terendahnya berkisar antara 210.000-410.000 rupiah dan harga tertingginya berkisar antara 970.0001.300.000 rupiah. Pada gambar 4 menjelaskan perkembangan harga lahan yang terjadi pada tahun 2014 adalah berada di sekitar Kelurahan Juwet Kenongo dan Porong.

Dalam perkembangannya, dapat terlihat dalam peta bahwa harga lahan yang memiliki kisaran cukup tinggi semakin meluas di antara kedua kelurahan tersebut. Pada tahun 2015 harga terendahnya berkisar antara 350.000-580.000 rupiah dan harga tertingginya berkisar antara 1.100.000-1.500.000 rupiah. Perkembangan yang terjadi dari tahun 2014 ke tahun 2015 dapat terlihat dalam gambar 4 dan 5 bahwa harga lahan pada tahun 2015 mengalami perembetan perkembangan di sekitar pusat kegiatan dan koridor Jalan Arteri.

\section{KESIMPULAN}

Berdasarkan pemetaan persebaran harga lahan yang telah dilakukan dapat diketahui bahwa pada tahun 2013-2015 telah terjadi perkembangan pola harga lahan di wilayah penelitian. Pada tahun 2013 ke tahun 2014, harga lahan di wilayah penelitian berkembang di sekitar Kelurahan Juwet Kenongo dan Porong yang merupakan pusat kegiatan. Dalam perkembangannya, dapat terlihat dalam peta bahwa harga lahan yang memiliki kisaran cukup tinggi semakin meluas di antara kedua kelurahan tersebut, sehingga pola harga lahannya memusat di pusat kegiatan. Harga tertinggi pada tahun 2013 ke tahun 2014 berselisih sebesar 120.000 hingga 200.000 rupiah. Pada tahun 2015 harga lahan mengalami perembetan pola perkembangan yang semakin meluas di sekitar pusat kegiatan dan mulai timbul perkembangan harga lahan yang cukup tinggi di sepanjang koridor Jalan Arteri, sehingga pada tahun 2015 pola perkembangannya cenderung mengarah ke pusat kegiatan tepatnya di perpotongan jalan arteri dan jalan kolektor, serta di sepanjang koridor jalan arteri. Dari hasil tersebut dapat disimpulkan bahwa terdapat titik-titik utama yang menjadi penyebab perkembangan harga lahan, yaitu Jalan Arteri dan pusat kegiatan.

\section{UCAPAN TERIMA KASIH}

Penulis N.F.A. mengucapkan terima kasih kepada dosen pembimbing penelitian, Ardy Maulidy Navastara, ST., MT yang telah banyak memberikan kritik dan saran membangun demi terselesaikannya penelitian ini dengan baik dan maksimal. Penulis juga mengucapkan terima kasih kepada pihak-pihak terkait yang menjadi sumber dan/atau responden yang membantu menyukseskan penelitian ini.

\section{DAFTAR PUSTAKA}

[1] Koestoer, Raldi Hendro. 2007. Perspektif Lingkungan Desa-Kota: Teori dan Kasus. Jakarta: UI Press.

[2] Yunus, Hadi Sabari. 2008. Dinamika Wilayah Peri-Urban Determinan Masa Depan Kota. Yogyakarta: Pustaka Pelajar. 
[3] Wicaksono, Tangguh. 2011. Analisis Faktor-Faktor yang Mempengaruhi Perubahan Pemanfaatan Perumahan Untuk Tujuan Komersial di Kawasan TLogosari Kulon, Semarang. Skripsi, Fakultas Ekonomi Universitas Diponegoro. Semarang.

[4] Yunus, Hadi Sabari. 1999. Struktur Tata Ruang Kota. Yogyakarta: Pustaka Pelajar.

[5] Badan Perencanaan dan Pembangunan Daerah Kabupaten Sidoarjo. 2009. Rencana Tata Ruang Wilayah Kabupaten Sidoarjo 2009-2029. Bapedda Kabupaten Sidoarjo. Sidoarjo.

[6] Anonim. http://rumahdijual.com/surabaya/714568-miliki-segerasebelum-kehabisan-kavlingan-di-lokasi-

strategis.html?from=http $\% 3 A \% 2 F \% 2$ Frumah.trovit.co.id\%2Findex.php $\% 2$ Fcod.frame\%2Furl.http\%25253A\%25252F\%25252Frumahdijual.co m\%25252Fsurabaya\%25252F714568-miliki-segera-sebelum-

kehabisan-kavlingan-di-lokasi-strategis.html\%2Fid_ad.-

113F1PCKR\%2Fwhat_d.tanah\%2520porong\%2520sidoarjo\%2Ftype.1 $\% 2$ Forigin.2\%2Fsection.1\%2Fsection_type.1\%2Fpop.1 (Diakses pada tanggal 13 Maret 2015 pada pukul 19.00 WIB)

[7] Navastara, Ardy M., dan Navitas, Prananda. 2012. Impact of Residential Development Towards Land Price Dynamics in Surabaya. ResearchGate Publication. 